\title{
On Redeployment to Palliative Care
}

\author{
Felipe Castillo ${ }^{1}$
}

Received: 4 June 2020 / Accepted: 20 October 2020 / Published online: 10 November 2020

(C) Academic Psychiatry 2020

"the virus is not that deadly you know"

"sabemos que la mayoría de nuestros pacientes con este cuadro al ser intubados no vuelven al mismo estado de salud y muchos no sobreviven"

("we know that the majority of our patients who are intubated with this clinical picture do not return to the same level and many do not survive.")

For the past few months, the contrast of opposing ideas above made it difficult to navigate extremes, mainly because the COVID-19 pandemic has challenged our ability to resolve the ambivalence surrounding them. It has been both the end of the world and business as usual. Nothing has happened yet everything has happened during this time. I bore witness to this conflict play out when I transitioned from the role of researcher working on the national opioid overdose epidemic to the front lines of the pandemic, providing palliative care.

Like many trainees, I was redeployed when my hospital could not keep up with staffing demands due to increased patient volume $[1,2]$. I paused my own training in addiction psychiatry to join the palliative care service, as we needed physicians capable of supporting patients and their families and conducting conversations to elicit goals of care in the emergency rooms and ICUs. My tasks turned out to be much more than that: I assisted in repositioning patients into the prone recovery position, held an iPad at the bedside for last goodbyes, and grieved deaths with primary teams. As a native Spanish speaker, I provided care in patients' preferred language, as phone interpretation quickly became challenging and impractical in the setting of noise interference from oxygen flow and other factors [3, 4]. Native language gifts were in high demand for navigating difficult discussions about

Felipe Castillo

felipe.castillo@nyspi.columbia.edu

1 Columbia University Irving Medical Center and New York State Psychiatric Institute, New York, NY, USA advance directives under circumstances extraordinarily pressured by lack of time and severity of symptoms. As soon as I got called in, I experienced my own internal conflict: I wanted to head in, and I also wanted to stay safe at home. I was ambivalent. I asked for an extra day before starting because I was afraid of getting sick. It was fortunately granted.

Once in the hospital, I saw how extensive the redeployment was: researchers from cardiology and endocrinology were taking care of patients with COVID, away from their labs and back on the wards as well. Our patients have been largely from uptown Manhattan and the Bronx, immigrant and Latino, struggling to find help in the face of such uncertainty and injustice evidenced by the unequal death toll in our communities [5]. How dangerous is this virus? What are the options when facing the choice of whether to intubate or not and to resuscitate or not? These choices, presented in a loud, foreign, isolated room, possibly abruptly, and within a healthcare system, on the verge of collapse naturally evoked fear and ambivalence. There was the hope that intubation would cure the illness. There was the hope that the procedures would be free of risk and free of pain. There was the hope that death could be full of dignity regardless of whether the process was prolonged artificially. And lastly, there was the hope that it was not just yet the time to pass away and say the final goodbye.

Over the cacophony of video conference calls and beeping drips, I heard this mix of emotions repeatedly from those who ultimately died, and from those who fortunately recovered, leaving the hospital with flowers, balloons, and elbow bumps. All I could do was to guide them through this ambivalence in a way that was consistent with their values. This ambivalence surrounding intubation, resuscitation, and withdrawing or maintaining life-prolonging treatment drew me in intellectually. I explored the feelings of being pushed and pulled in multiple directions and to accept them as valid even if unpleasant. I held on: I was there to listen to the values held, and by reflecting that ambivalence, pain was mitigated and end of life decisions made less distressing. I brought my previous training as a psychiatrist to this new role. The central 
tenets of psychotherapy allowed for some discomfort to dissipate: we provided healing by listening well. When one of the patient's families started to discuss what making a change in the code status would look like, I mentioned to my palliative care attending physician supervisor that they were expressing "change talk." She was initially unfamiliar with the term I used but immediately understood it once I provided the definition. Her version of "ask-tell-ask" was my "elicit-provideelicit," and helping people navigate difficult choices using techniques from various types of therapy may have just been "really good listening" at time of need. I was left wondering if this reshuffle will continue to promote the cross-pollination of ideas across our hyperspecialized disciplines.

In this rapidly evolving panorama, we are returning to our previous roles: to routine check-ups, tissue staining, and non-inferiority studies - but also returning to other current health crises including gun violence, heart disease and stroke, road-related trauma, dementia, diabetes, HIV infections and AIDS, cancer, racism, economic insecurity, and the opioid overdose epidemic. While we will carry the trauma we experienced, we also return having learned new skills. I for one, expect to return to my role as an addiction researcher better equipped to address the poor prognoses, the injustices due to social determinants of health, and the trauma from premature morbidity and untimely deaths often associated with drug use. I will approach suffering with more humility, recognizing the lack of knowledge, barriers to implementation of effective measures, and the entrenched prejudices in our medical system, all while acting to dismantle them. This experience has solidified my commitment to lifelong learning as a doctor and nurtured my hope that we continue to share knowledge across our hyperspecialized fields. I wish that if we ever have a rapid, massive redeployment of physicians to combat the overdose epidemic, physicians from other fields can serve in our mission and teach us what they know. Well, one can dream. "Soñar no cuesta nada." ("one can always dream")

Acknowledgments Special thanks to Daniel Shalev, MD, and Ana Berlin, MD, for their contributions to this viewpoint.

\section{Compliance with Ethical Standards}

Disclosures On behalf of all authors, the corresponding author states that there is no conflict of interest.

\section{References}

1. Cummings MJ, Baldwin MR, Abrams D, Jacobson SD, Meyer BJ, Balough EM, et al. Epidemiology, clinical course, and outcomes of critically ill adults with COVID-19 in New York City: a prospective cohort study. Lancet Lond Engl. Published online May. 2020;19: 1763-70. https://doi.org/10.1016/S0140-6736(20)31189-2.

2. Shalev D, Nakagawa S, Stroeh OM, Arbuckle MR, Rendleman R, Blinderman $\mathrm{CD}$, et al. The creation of a psychiatry-palliative care liaison team: using psychiatrists to extend palliative care delivery and access during the COVID-19 crisis. J Pain Symptom Manage. 2020;60(3):e12-6. https://doi.org/10.1016/j.jpainsymman.2020.06. 009.

3. Silva MD, Genoff M, Zaballa A, Jewell S, Stabler S, Gany FM, et al. Interpreting at the end of life: a systematic review of the impact of interpreters on the delivery of palliative care services to cancer patients with limited English proficiency. J Pain Symptom Manage. 2016;51(3):569-80. https://doi.org/10.1016/j.jpainsymman.2015. 10.011 .

4. Bauer AM, Alegría M. Impact of patient language proficiency and interpreter service use on the quality of psychiatric care: a systematic review.Psychiatr. Serv. 2010;61(8):765-73. https://doi.org/10.1176/ ps.2010.61.8.765.

5. Wadhera RK, Wadhera P, Gaba P, Figueroa JF, Joynt Maddox KE, Yeh RW, et al. Variation in COVID-19 hospitalizations and deaths across New York City boroughs. JAMA Published online April. 2020;29:2192-5. https://doi.org/10.1001/jama.2020.7197.

Publisher's Note Springer Nature remains neutral with regard to jurisdictional claims in published maps and institutional affiliations. 